\title{
$1-1$
}

\section{HLB 温度に及ぼす親油性両親媒性化合物の添加効果}

\author{
岩永 哲朗*1 ・塩貝 芳樹 ${ }^{* 1} \cdot$ 國枝 博信 ${ }^{* 2}$ \\ *1 (株)ノエビア滋賀中央研究所 (下527 八日市市岡田町 112-1) \\ $* 2$ 横浜国立大学大学院 工学研究科 人工環境システム学専攻 (テ240 横浜市保土ヶ谷区常盤台 79-5)
}

\section{Effects of Added Lipophilic Amphiphiles on HLB Temperature}

\author{
Tetsurou IwANAGA ${ }^{* 1}$, Yoshiki ShIOGA ${ }^{* 1}$, and Hironobu KuniedA ${ }^{* 2}$ \\ *1 Shiga Central Research Laboratory, Noevir Co., LTD. \\ (Okada-cho 112-1, Youkaichi-shi, T527) \\ *2 Division of Artificial Environmental Systems, Graduate School of Engineering, \\ Yokohama National University \\ (Tokiwadai 79-5, Hodogaya-ku, Yokohama-shi, $\mathbf{T} 240$ )
}

\begin{abstract}
HLB temperature (or PIT) of octaoxyethylene dodecyl ether $\left(\mathrm{C}_{12} \mathrm{EO}_{8}\right)$ in a water-decane system $\left(81.5^{\circ} \mathrm{C}\right)$ has been shown to decrease with the addition of a lipophilic amphiphile such as monolaurin or 1-dodecanol. In the monolaurin system, HLB temperature decreased regardless of total surfactant concentration while in the 1-dodecanol system, increased to nearly resume that of $\mathrm{C}_{12} \mathrm{EO}_{8}$ with decrease total surfactant concentration. The difference in phase behavior may possibly be due to the solubility of lipophilic amphiphile in the oil phase.

The correlation of change in HLB temperature with HLB number is discussed for both sys-
\end{abstract} tems.

Key words : HLB temperature, three-phase behavior, HLB number, polyoxyethylene dodecyl ether, lipophilic amphiphile

\section{1 緒 言}

ポリ(オキシエチレン) 型非イオン界面活性剂は温度 の上昇に伴い親水性から親油性に変化し，ちょうどバラ ンスの取れた温度，すなわち HLB 温度でマイクロエマ ルション相（界面活性剤相）を形成し，過剩の水相，油 相と 3 相共存領域を形成する ${ }^{1)}$ 。そこでは, 界面活性剂 の可溶化能力, 界面張力低下能等の機能は最大になり, 乳化の型も $\mathrm{O} / \mathrm{W}$ から W/O に転相する ${ }^{1), 2) 。 ~}$

単一鎖長のポリ (オキシエチレン) 型非イオン界面活 性剂の HLB 温度や, 界面活性剂相の性質はかなり研究 されており, 温度, 油の種類, 油水比の影響は明らかに

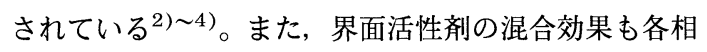
への分配を考慮して, 3 相平衡の幾何学的関係から半定 量的に表すことができる5) 8)。さらに, 多分散系であ る市販のポリ (オキシエチレン) 型非イオン界面活性剂 の溶存状態についても明らかにされている99,10)。 しかし, 例えば化粧品等の実際の応用を考えると, 高 連絡者 : 岩永哲朗
級アルコールのような親油性の両親媒性化合物を乳化安 定のための補助界面活性剂 (co-surfactant) として配 合することが多い。また，乳化安定性に及ぼす高級アル コールの効果については数多くの報告がある ${ }^{11) ~ 13) 。 ~}$ しかし, 非イオン界面活性剂-油一水の 3 成分系の溶存 状態に及ぼす co-surfactant の効果についてはあまり 行われていない。

本研究では, 単一鎖長のポリ(オキシエチレン)型非 イオン界面活性剤, 炭化水素, 水からなる 3 成分系での HLB 温度に及ぼす高級アルコール，モノアシルグリセ リンなどの親油性両親媒性化合物の添加効果を検討し た。

\section{2 実 験}

\section{$2 \cdot 1$ 試 料}

単一鎖長のオクタエチレングリコールモノドデシル エーテル $\left(\mathrm{C}_{12} \mathrm{EO}_{8}\right)$ 及びへキサエチレングリコールモ ノドデシルエーテル $\left(\mathrm{C}_{12} \mathrm{EO}_{6}\right)$ は(株) 日光ケミカルズ 社製のものを用いた。co-surfactant として 1-ドデカ 
ノール $\left(\mathrm{C}_{12} \mathrm{OH}\right), 1$-ラウロイルグリセリン (モノラウ

リン, $\mathrm{ML})$ を, 油成分としてヘプタン, デカンそして ヘキサデカンは, いずれも(株)東京化成工業社製（試薬 特級）のものをそのまま用いた。塩化ナトリウムは, 純 正化学株式会社製（試薬特級）をそのまま用いた。水は イオン交換水を二度蒸留したものを使用した。

\section{$2 \cdot 2$ 実験方法}

$2 \cdot 2 \cdot 1$ 相平衡図の作成

相平衡図は所定の組成のサンプルをアンプル中に封入 し, 恒温水槽中で振とう擋挥後, 静置し, その状態を観 察して求めた。液晶の有無は, 2 枚の偏光板を用いて確 認した。

$2 \cdot 2 \cdot 2$ 転相点の測定

転相点は, 電気伝導度計 $(\mathrm{CM}-40 \mathrm{~S}$, 東亜電波製) を 用いて電気伝導度の変化を追跡して求めた。測定温度は

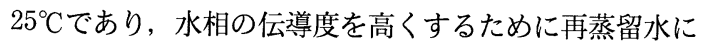
$0.01 \mathrm{M}$ 塩化ナトリウムを添加した。

\section{3 結果と考察}

\section{$3 \cdot 1 \quad$ 水 $/ \mathrm{C}_{12} \mathrm{EO}_{8} /$ デカン系の $\mathrm{HLB}$ 温度}

Fig. 1 に, 水 $/ \mathrm{C}_{12} \mathrm{EO}_{8} /$ デカンからなる 3 成分系の温 度変化を示す。水一油に対する油の重量分率 $\left(R_{\mathrm{OW}}\right)$ は 0.5 である。

低温側では界面活性剤が水中にミセル溶解し，可溶化 しきれない過剩の油を分離し二相系を形成する。温度上 昇と共に油の可溶化量は増し, 界面活性剂は界面活性剂 相（マイクロエマルション, D 相）として，水相から分 離し, 油相と併せて三相共存系（III）を形成する。この 3 相共存域の中間の温度は HLB 温度または乳化の転相 温度 (PIT) と呼ばれ, 図に示すように界面活性剂に対 する水, 油の可溶化量は極大になる。さらに高温側で は, D 相は油を多く含むようになり, 油相と相互溶解す る。その結果, 逆ミセル溶液相と過剩の水相の二相系に なる。界面活性剤が純粋な場合, HLB 温度は, 組成に

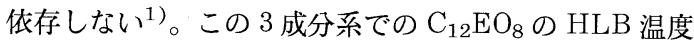
は $81.5^{\circ} \mathrm{C}$ である。

\section{$3 \cdot 2$ 水 $/ \mathrm{C}_{12} \mathrm{OH} / \mathrm{C}_{12} \mathrm{EO}_{8}$ /デカン系の相挙動}

Fig. 1 に, 水 $/ \mathrm{C}_{12} \mathrm{EO}_{8} /$ デカンの系に $\mathrm{C}_{12} \mathrm{OH}$ を添加 したときの溶存状態を示す。図中の $W_{1}$ は全界面活性剂 $\left(\mathrm{C}_{12} \mathrm{EO}_{8}+\mathrm{C}_{12} \mathrm{OH}\right)$ 中の $\mathrm{C}_{12} \mathrm{OH}$ の重量分率, $W_{2}$ は $\mathrm{C}_{12} \mathrm{EO}_{8}$ の重量分率を示す。

Fig. 1 に示すように, 混合界面活性剂濃度が低下す るにつれて 3 相領域は高温に上昇し, $\mathrm{C}_{12} \mathrm{EO}_{8}$ 単独の $\mathrm{HLB}$ 温度に近づく。しかも， $\mathrm{C}_{12} \mathrm{OH}$ の割合が増すに つれて 3 相領域の傾きは大きくなる。これは, 混合界面 活性剂 $\left(\mathrm{C}_{12} \mathrm{EO}_{8}+\mathrm{C}_{12} \mathrm{OH}\right)$ 中の親油性の界面活性剂の 油に対する溶解度が大きいため, D 相中の微細な油一水 界面での界面活性剤層の混合比率が仕込み比と異なり,

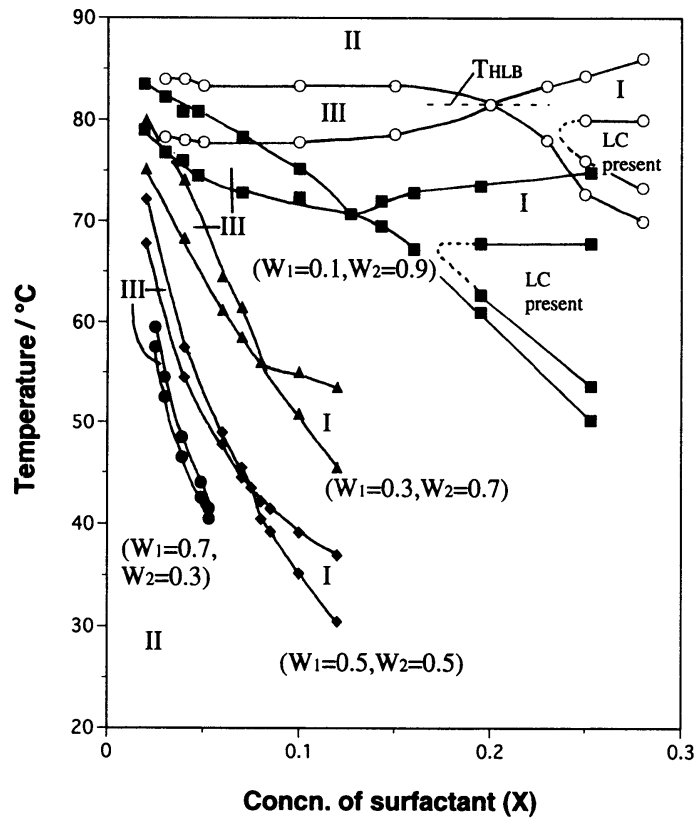

Fig. 1 The Phase Daigrams of Water $/ \mathrm{C}_{12} \mathrm{EO}_{8} /$ Decane $(\bigcirc)$ and Water/1-dodecanol $<1>/$ $\mathrm{C}_{12} \mathrm{EO}_{8}<2>/$ Decane Systems as a Function of Temperature.

The water/oil ratios are 50/50 (wt/wt). $\mathrm{W}_{1}$ and $\mathrm{W}_{2}$ are the weight fraction of 1 -dodecanol and $\mathrm{C}_{12} \mathrm{EO}_{8}$ in total surfactant, respectively. I, II, and III are one - , two-, and three-phase regions, respectively. "LC present" is a region including a liquid crystal. The broken line indicates HLB temperature.

$\mathrm{C}_{12} \mathrm{EO}_{8}$ の割合が多くなるためである ${ }^{3), 7), 8) 。 ~}$

$3 \cdot 3$ 水 $/ \mathrm{ML} / \mathrm{C}_{12} \mathrm{EO}_{8} /$ デカン系の相挙動

Fig. 2 に, 水 $/ \mathrm{C}_{12} \mathrm{EO}_{8}$ /デカンの系に $\mathrm{ML}$ を添加した ときの溶存状態を示す。この系についても $\mathrm{C}_{12} \mathrm{OH}$ 添加 系と同様に混合比率を変えて検討した。

ML の比率が増すにつれて HLB 温度は低温側に移行 する傾向がみられた。しかし, 前系とは異なり混合比率 を固定すると混合界面活性剂濃度に依存せず HLB 温度 は一定となった $)^{5)}$ これは, ML は親油性が強いにもか かわらず, $\mathrm{C}_{12} \mathrm{OH}$ のように油に溶解せず効率よく油水 界面に配列するためと考えられる。以上の結果から明ら かなように, 親油性の両親媒性物質を添加した時, 油へ の溶解性の違いから, HLB 温度の変化は大きく異な る。

\section{$3 \cdot 4$ 混合界面活性剂の油相中の溶解度}

3 相平衡の解析から, 混合界面活性剂 2 成分と油, 水 を含む 4 成分系では, HLB 温度を示す組成は次の関倸 にあることが示されている5) 8)。 


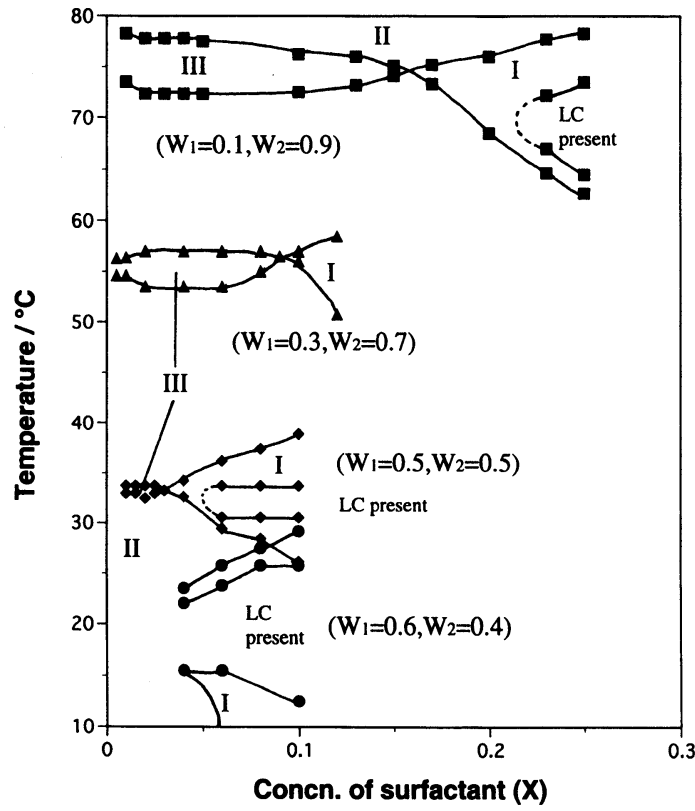

Fig. 2 The Phase Diagrams of Water/Monolaurin $<1>/ \mathrm{C}_{12} \mathrm{EO}_{8}<2>/$ Decane Systems as a Function of Temperature.

The water/oil ratios are 50/50 (wt/wt). $\mathrm{W}_{1}$ and $\mathrm{W}_{2}$ are the weight fraction of monolaurin and $\mathrm{C}_{12} \mathrm{EO}_{8}$ in total surfactant, respectively. I, II, and III are one-, two-, and three-phase regions, respectively. " $\mathrm{LC}$ present" is a region including a liquid crystal.

$$
W_{1}=S_{1}^{\mathrm{S}}+\frac{S_{1} S_{2}^{\mathrm{S}}-S_{2} S_{1}^{\mathrm{S}}}{1-S_{1}-S_{2}} R_{\mathrm{OW}}\left(\frac{1}{x}-1\right)
$$

ここで, $R_{\mathrm{OW}}$ は油/(油十水) を, $x$ は全界面活性剤 の系に対する重量分率を表し， $W_{1}$ は，混合界面活性剂 中の co-surfactant の重量分率で, $S_{1}, S_{2}$ は, 油相中 の co-surfactant 及び非イオン界面活性剂の油に対す る重量分率, $S_{1}^{\mathrm{S}}, S_{2}^{\mathrm{S}}$ は D 相中の水-油界面の界面活性 剤層中の co-surfactant 及び非イオン界面活性剂の重 量分率である。また, 以前の報告により次式が成立す $ろ^{5)}$ 。

$$
T=T_{1}^{\mathrm{HLB}} S_{1}^{\mathrm{S}}+T_{2}^{\mathrm{HLB}} S_{2}^{\mathrm{S}}\left(S_{1}^{\mathrm{S}}+S_{2}^{\mathrm{S}}=1\right)
$$

ここで, $T_{1}^{\mathrm{HLB}}$ と $T_{2}^{\mathrm{HLB}}$ は, 各界面活性剂単独の

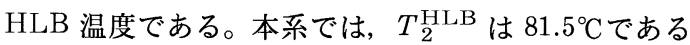
が, $T_{1}^{\mathrm{HLB}}$ は $\mathrm{ML}, \mathrm{C}_{12} \mathrm{OH}$ とも実際には出現しない。 $T$ は, 混合界面活性剂の HLB 温度で 3 相領域の中間の 温度である。また, 添字の 1 と 2 は, 以下ではそれぞれ co-surfactant と非イオン界面活性剂を示す。 式 (1), (2) より以下のように変形できる7)。

$$
\begin{aligned}
& T=K(T) R_{\mathrm{OW}}\left(\frac{1}{x}-1\right)+\left(T_{1}^{\mathrm{HLB}} W_{1}+T_{2}^{\mathrm{HLB}} W_{2}\right) \\
& K(T)=\frac{\left(T-T_{1}^{\mathrm{HLB}}\right) S_{1}+\left(T-T_{2}^{\mathrm{HLB}}\right) S_{2}}{1-S_{1}-S_{2}}
\end{aligned}
$$

式 $(4)$ より, $K(T)$ は, 温度, $S_{1}$ そして $\mathrm{S}_{2}$ の関数であ り, $S_{1}$ と $S_{2}$ は, 温度の関数でもある。 $\mathrm{C}_{12} \mathrm{OH}$ 及び ML 添加系 (Fig. 1，2) での 3 相領域の中間の温度 (HLB 温度) と $1 / x-1$ の值をプロットしたものを Fig. 3,4 に示す。 $\mathrm{C}_{12} \mathrm{OH}$ 添加系では, $x$ が小さいとき直線 関係が成り立つが， $\mathrm{C}_{12} \mathrm{OH}$ の混合割合が増すにつれて 直線の傾きが大きくなっている。この傾きは式 (3) の $K(T)$ に相当する。以前のポリ (オキシエチレン) 型非 イオン界面活性剂混合系の相挙動の結果から ${ }^{8)}, S_{1}$ と $S_{2}$

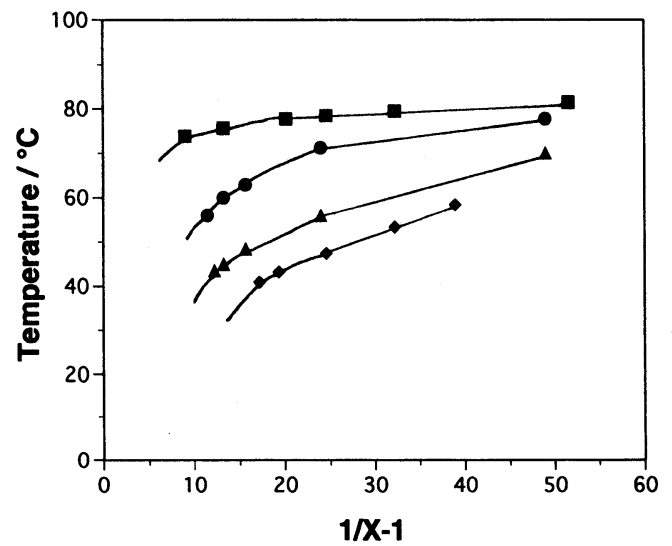

Fig. 3 The Plots of Mid Temperature in Fig. 1 against $1 / x-1$.
: $\mathrm{W}_{1}=0.1$,
$\checkmark: \mathrm{W}_{1}=0.7$.
: $\mathrm{W}_{1}=0.3$
$\boldsymbol{\Delta}: \mathrm{W}_{1}=0.5$,

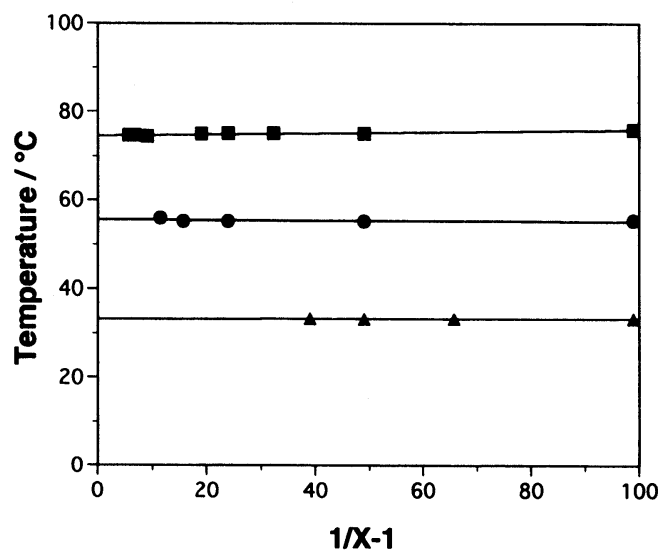

Fig. 4 The Plots of Mid Temperature in Fig. 2 against $1 / x-1$.
घ: $\mathrm{W}_{1}=0.1$,
$\mathrm{W}_{1}=0.3$
$\Delta: \mathrm{W}_{1}=0.5$. 
はきっ抗する関係にあり, 温度上昇とともに $S_{1}$ は減少 し $S_{2}$ は上昇する。もし, 本系においても同様な関係が 成立するならば, 本来 $S_{1}>>S_{2}$ なので, $K(T)$ の傾き が低温部, 高濃度側で急になるのは, 主に $S_{1}$ の増加と 考えられる。一方, ML 添加系では, ML の混合比率が 增しても傾きはほぼ 0 であり, $\mathrm{ML} も \mathrm{C}_{12} \mathrm{EO}_{8}$ も油への 溶解度が極めて小さいことを示している。

3.5 親油性両親媒性化合物の HLB 温度と HLB number

$$
3 \cdot 5 \cdot 1 \text { モノラウリン (ML) }
$$

Fig. 4 の直線を $x=1$ にすなわち界面活性剂の濃度 100 $\%$ に補外したときの $\mathrm{Y}$ 軸との交点は式 (3)の $T_{1}^{\mathrm{HLB}} W_{1}$ $+T_{2}^{\mathrm{HLB}} W_{2}\left(=\sum_{\mathrm{i}} T_{\mathrm{i}}^{\mathrm{HLB}} W_{\mathrm{i}}\right)$ で, 油中への単分散濃度に 無関係でその混合界面活性剂系に固有な HLB 温度であ る。ただし， $\mathrm{C}_{12} \mathrm{OH}$ 系 (Fig. 3) は傾きが変わるために 補外はできない。Fig. 4 の切片から読み取った ML と $\mathrm{C}_{12} \mathrm{EO}_{8}$ の混合界面活性剂の HLB 温度と組成比の関係 をFig. 5 に示す。これらの值を用いて ML の HLB number を求めた。計算には, 以下の 2 式を用いた5)。

$$
\begin{aligned}
& T=T_{1}^{\mathrm{HLB}} W_{1}+T_{2}^{\mathrm{HLB}} W_{2}=\sum_{\mathrm{i}} T_{\mathrm{i}}^{\mathrm{HLB}} W_{\mathrm{i}} \\
& T_{\mathrm{i}}^{\mathrm{HLB}}=k_{\text {oil }}\left(N_{\mathrm{i}}^{\mathrm{HLB}}-N_{\text {oil }}\right)
\end{aligned}
$$

ここで, $T$ は, 混合界面活性剂の HLB 温度で, $T_{\mathrm{i}}^{\mathrm{HLB}}$ と $N_{\mathrm{i}}^{\mathrm{HLB}}$ は, $\mathrm{i}$ 成分界面活性剂の HLB 温度と HLB number である。 $N_{\mathrm{i}}^{\mathrm{HLB}}$ は, i 成分の界面活性剂の HLB number である。 $k_{\text {oil }}$ は, 定数で多くの油に対し てほぼ $17^{\circ} \mathrm{C} / \mathrm{HLB}$ になり, $N_{\text {oil }}$ は, 油に対する定数で ある。計算に当たって, デカンの $N_{\text {oil }}$ は 8.5 とした。

$\mathrm{HLB}$ 温度が $25^{\circ} \mathrm{C}$ の時の $\mathrm{ML}$ と $\mathrm{C}_{12} \mathrm{EO}_{8}$ の組成を図 より読み取り, MLの HLB number を求めた。この時 の $\mathrm{ML}$ と $\mathrm{C}_{12} \mathrm{EO}_{8}$ の組成は, それぞれ $W_{1}=0.57$ と $W_{2}$ $=0.43$ である。式 (5) より ML の HLB 温度は, -17.6 ${ }^{\circ} \mathrm{C}$ と求まる。よって, 式 (6) より ML の HLB number は 7.5 となる。また, Griffin の式 ${ }^{14)}$ から計算され る HLB number は 6.6 でほぼ妥当な值となった。

\section{$3 \cdot 5 \cdot 2$ 1-ドデカノール $\left(\mathrm{C}_{12} \mathrm{OH}\right)$}

$\mathrm{C}_{12} \mathrm{OH}$ 添加系では温度上昇に伴い $S_{1}$ が大きく変化 するため式 (3) の $K(T)$ は一定にならないと考えられ る。一方, 一定温度で式 (1) は, 一般的に成立すること が確認されている5),7),8),10)。そこで, $\mathrm{C}_{12} \mathrm{OH}$ の Griffin の HLB number が 0 であることを確認するため,

一定温度 $\left(25^{\circ} \mathrm{C}\right)$ で, 界面活性剂の混合割合を変えて, 3 相領域すなわち PIT を伝導度法により求めた。実験 は, 水 $/ \mathrm{C}_{12} \mathrm{EO}_{8} / \mathrm{C}_{12} \mathrm{OH} /$ ヘキサデカン, 水 $/ \mathrm{C}_{12} \mathrm{EO}_{8} /$ $\mathrm{C}_{12} \mathrm{OH} /$ ヘプタンそして水 $/ \mathrm{C}_{12} \mathrm{EO}_{6} / \mathrm{C}_{12} \mathrm{OH} /$ デカンの 3 種類の系で行った。これらの結果を Fig. 6 に示す。

$x=1$ へ補外したときの切片は, 式(2)より $W_{1}=S_{1}^{\mathrm{S}}$ で ある。ところで, $S_{1}^{\mathrm{S}}$ は, 式 (2), (6) より計算により求 めることができる。計算に当たって, $\mathrm{C}_{12} \mathrm{OH}$ の HLB

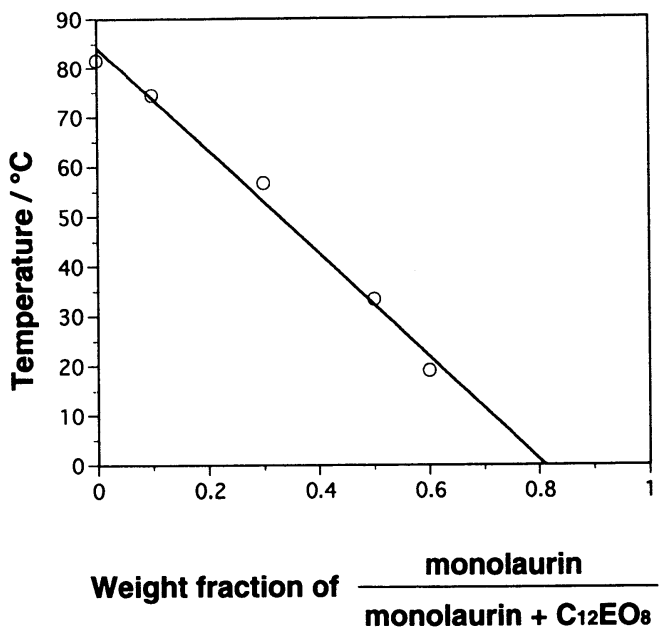

Fig. 5 The Plot of HLB Temperature against the Weight Fraction of Monolaurin.

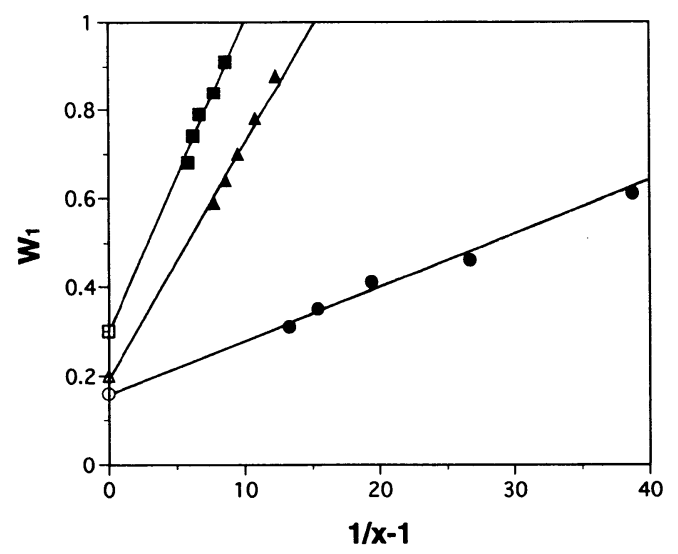

Fig. $6 \mathrm{~W}_{1}$ Measured by Electrical Conductivity Plotted against $1 / x-1$.

口 : a water $/ \mathrm{C}_{12} \mathrm{EO}_{8} / 1$-dodecanol/hexadecane system at $25^{\circ} \mathrm{C}$. $\mathrm{O}$ : a water $/ \mathrm{C}_{12} \mathrm{EO}_{6} /$ 1 -dodecanol/decane system at $25^{\circ} \mathrm{C}$. $\boldsymbol{\Delta}$ : a water $/ \mathrm{C}_{12} \mathrm{EO}_{8} / 1$-dodecanol/heptane system at $25^{\circ} \mathrm{C}$. $\mathrm{W}_{1}$ is the weight fraction of 1-dodecanol in total surfactants at the phase inversion points. $\square, \bigcirc, \triangle$ are calculated by Eqs. (2) and (6).

number を Griffin の式から想定されるように0 0 と、へ キサデカンとヘプタンの $N_{\text {oil }}$ は, それぞれ 7.7 と 8.9 と した。その結果, ヘキサデカン系で $S_{1}^{\mathrm{S}}=0.3$, ヘプタン 系で $S_{1}^{S}=0.2$ そしてデカン系で $S_{1}^{\mathrm{S}}=0.16$ が求まる。こ れらは, 縦軸の切片に相当する。Fig. 6 に示すよう に, これらの值と伝導度で求めた值を結ぶと直線関係が 成立する。式(1)の $S_{1}, S_{2}, S_{1}^{\mathrm{S}}, S_{2}^{\mathrm{S}}$ は, 温度が一定だと 定数になり 3 相領域の中間組成(乳化の転相点, PIT) と 
$1 / x-1$ は必ず直線になるはずである。従って, 0 と仮定 した $\mathrm{C}_{12} \mathrm{OH}$ の HLB number は妥当と考えられる。

（受付 : 1996 年 11 月 15 日, 受理 : 1997 年 2 月 28 日）

\section{文献}

1) K. Shinoda, H. Saito, J. Colloid Interface Sci., 26, 70 (1968).

2) H. Kunieda, K. Shinoda, Bull. Chem. Jpn., 55, 1777 (1982).

3) H. Kunieda, K. Shinoda, Bull. Chem. Jpn., 54, 1010 (1981).

4) H. Kunieda, A. Miyajima, J. Colloid Interface Sci., 128, 605 (1989).

5) H. Kunieda, K. Shinoda, J. Colloid Interface Sci.,
107, 107 (1985).

6) H. Kunieda, N. Ishikawa, J. Colloid Interface Sci., 107, 122 (1985).

7) H. Kunieda, M. Yamagata, Coll. Polym. Sci., 271, 997 (1993).

8) H. Kunieda, M. Yamagata, Langmuir, 9, 3345 (1993).

9) 国枝博信, 篠田耕三, 油化学, 34, 367 (1985).

10) 武藤正和, 内藤 昇, 国枝博信, 油化学, 43, 502 (1994).

11）山口道広, 高橋元次, 春沢文則, 福島正二, 粧技誌, 12, 16 (1978).

12）鈴木敏幸, 油化学, 35, 113 (1986).

13) 福島正二, 山口道広, 油化学, 29, 106 (1980).

14) W.C. Griffin, J. Soc. Cosmet. Chem., 5, 249(1954). 


\title{
[ノート］ガマの花粉に含まれる植物ステロールの組成
}

\author{
高津戸 秀 \\ 上越教育大学自然系化学教室 $($ ( 943 新潟県上越市山屋敷町 1$)$
}

ガマ (ガマ科) の花粉に含まれる植物ステロールの組成について調べた。メタノール抽出物より得たへキサン可 溶分画を加水分解し, 不けん化脂質を精製して植物ステロール分画を得た。この分画を TMS 化後, GC-MS 分析 を行った。その結果，6種のステロール（コレステロール，24-メチレンコレステロール，カンペステロール，スチ グマステロール， $\beta$-シトステロールおよびイソフコステロール）を同定した。24-メチレンコレステロールとイソ フコステロールは花粉では主成分であるが，ガマの花粉においてはこれら 2 種のステロールは共に微量成分とし て，また， $\beta$-シトステロールは主成分（約 85\%）として同定した。

(連絡者:高津戸 秀) Vol. 46, No. 6, 687 (1997)

$[$ ノート $]$

\section{HLB 温度に及ぼす親油性 両親媒性化合物の添加効果}

\section{岩永 哲朗*1・塩貝 芳樹*1 ・國枝 博信*2}

*1 (株)ノエビア滋賀中央研究所 (厂527 八日市市岡田町 112-1)

$* 2$ 横浜国立大学大学院工学研究科人工環境システム学専攻 (テ240 横浜市保土ヶ谷区常盤台 79-5)

水-デカン系におけるオクタエチレングリコールドデシルエーテル $\left(\mathrm{C}_{12} \mathrm{EO}_{8}\right)$ の HLB 温度または PIT $\left(81.5^{\circ} \mathrm{C}\right)$ は，両親媒性化合物（モノラウリン，1-ドデカノール）の添加により減少した。モノラウリン添加系における, 低 下した HLB 温度は, 全界面活性剂濃度の変化によって影響を受けないが, 1-ドデカノール添加系では, 全界面活 性剂の濃度が低下するに従って HLB 温度は上昇し, $\mathrm{C}_{12} \mathrm{EO}_{8}$ 単独の HLB 温度に近づく。これらの異なった相挙 動は, 油中の親油性両親媒性化合物の溶解性の違いによるものである。

両系について, HLB 温度の変化と HLB number の関係を議論した。

（連絡者：岩永哲朗）Vol. 46, No. 6, 691 (1997)

\section{$[$ ノート]}

.

深津

\section{高速液体クロマトグラフィーを用いた \\ リパーゼ活性の測定}
*2 Canadian Grain Commission/Grain Research Laboratory
(1404-303 Mail St. Winnipeg, MB R3C 3C8, Canada)

リパーゼ単位はある条件下で $1 \mathrm{~min} に 1 \mu \mathrm{mol}$ の遊離脂肪酸を生成する酵素量と定められている。遊離脂肪酸の 量は中和滴定で求めるのが一般的である。この定量分析を高速液体クロマトグラフィー (HPLC) 法で置き換え た。気化光散乱検出器を備えた HPLC を用いて遊離脂肪酸を测定することで Candida cylindracea 由来のリ パーゼの活性を測定した。HPLC 法は滴定法と同じ結果を与えたが，感度はより高かった。

（連絡者: 深津 誠）Vol. 46, No. 6, 697 (1997) 